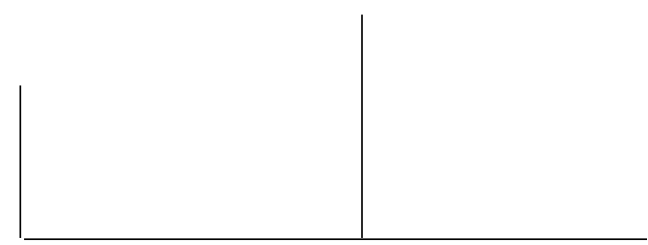

Rev. Latinoam. Psicopat. Fund., VIII, 2, 274-288

\title{
Psicossomática: historicidade ou atualidade?
}

\author{
Rogério Robbe Quintella
}

Procuramos aqui abordar a questão da concepção de historicidade em psicanálise, em contraponto ao conceito de neurose "atual”, o qual serve de base para a teorização contemporânea em psicossomática. Realizamos uma revisão crítica da neurose atual, sob o prisma de uma aglutinação neurose atual-psiconeurose, concebendo historicidade e sexualidade articuladas ao nível da linguagem. Finalmente, sugerimos que a neurose atual deve ser abordada a partir desse nível, visto sua ligação com a psiconeurose, o que pode nos fornecer novas bases para pensarmos o fenômeno psicossomático.

Palavras-chave: Neurose atual, psiconeurose, historicidade, sexualidade, linguagem 
A psicanálise se funda a partir de conceitos estabelecidos por Freud no movimento de investigação realizado com pacientes que apresentavam “doenças nervosas”, ligadas a processos psíquicos, as quais constituíram para Freud um vasto terreno de teorização, cuja peça fundamental se presentificou no conceito de inconsciente (Freud, 1900). Percebe-se, no percurso de constituição deste conceito, que todo seu empenho no sentido de buscar os fatores determinantes geradores dos sintomas manifestos em seus pacientes revela, de maneira clara e inequívoca, o fato de que, desde os primórdios de sua teoria, seu interesse centrava-se fundamentalmente na história individual dos pacientes. Freud (1893) questionava-se amplamente sobre "lembranças" do passado que estariam causando a patogenia manifesta, idéias incompatíveis sobre fatos traumáticos da infância que pareciam encontrar-se na gênese de cada sintoma.

Diante de freqüentes fracassos com o método hipnótico, ele se viu impelido a promover mudanças em sua técnica, que o levaram cada vez mais perto da regra da livre associação de idéias. Trabalhando arduamente a respeito de casos tratados através do método da "pressão na testa" - como se constata em um de seus textos mais antigos, "A psicoterapia da histeria" (1893) - iniciava sua trilha para a formulação do conceito de inconsciente e para a criação da psicanálise. Segundo este método, persuadia seus pacientes a relatar as idéias que emergiam de sua mente no momento em que aplicava a pressão. A partir disso, destacava séries de elementos ideativos aparentemente desconexos e reconstituía-os de acordo com as lembranças e relatos que ouvia. Chegava à conclusão de que esses elementos estavam associados entre si e a fatores importantes da história do indivíduo, os quais eram concebidos como "representações patogênicas”, lembranças de traumas da infância ligadas a cenas de abuso sexual realizados por parte de adultos, fatores que acreditava estarem na raiz dos sintomas neuróticos.

Neste mesmo movimento inicial, quando ainda a psicanálise estava em vias de ser criada, Freud (1898) fez importantes distinções entre fenômenos diversos, baseado em constatações clínicas que o levaram a pensar a importância do fator sexual que envolve essas patogenias. Distinguindo e classificando dois grupos de neuroses - as neuroses atuais e as psiconeuroses - concluiu que o eixo principal de todas elas encontra-se num conflito de natureza sexual, quer por implicações contemporâneas da atividade 


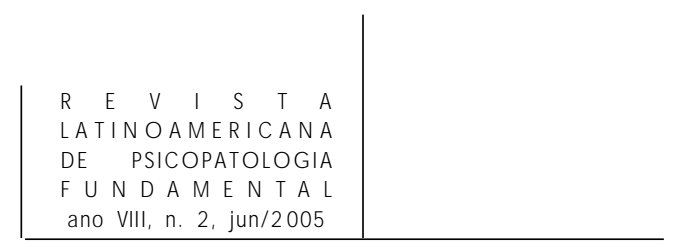

sexual do indivíduo - resultado de conseqüências diretas oriundas dessa atividade (neuroses atuais) -, quer por fatores anteriores, históricos, da sexualidade do indivíduo - resultado do recalcamento de uma representação incompatível na consciência (psiconeuroses) ${ }^{1}-(1906)$. A oposição entre neuroses atuais e psiconeuroses - esse é o ponto onde desejamos nos centrar - encontra-se no caráter de historicidade dos fatores sexuais que envolvem a sintomatologia psiconeurótica. Os sintomas das neuroses atuais, de características eminentemente somáticas, não eram claramente associados, na fala dos pacientes, a fatores sexuais históricos, não eram 'historicizados' como no caso das psiconeuroses. Estavam ligados, segundo Freud (1898), a fatores sexuais contemporâneos à vida sexual do indivíduo. Por esse motivo, esses sintomas foram englobados numa categoria que recebeu dele a denominação de "neurose atual".

O conceito de neurose atual foi amplamente utilizado por autores empenhados com a questão psicossomática, dentre os quais se destacam Marty, Fain, M’Uzan, tendo sido tomado como modelo e base para a constituição teórica acerca deste tema (Ferraz, 1997).

Avaliamos relevante, numa discussão detalhada acerca da concepção de historicidade em psicanálise, articular e desenvolver o fator de oposição historicidade/atualidade na apreensão dos dois grupos de neuroses mencionados acima, dimensionando-se a questão da psicossomática para futuras indagações, já que o conceito de neurose atual serve de base, até então, para as referidas abordagens em psicossomática. Cabe lembrar ainda, a estreita conexão existente entre o fenômeno da neurose atual e o fenômeno da psiconeurose demonstrada por Freud, conexão apontada alhures por Quintella (2003) como situação problemática para estas abordagens.

\section{História e representação}

Os textos iniciais de Freud, como apontamos, revelam-nos que a especificidade de sua teoria está centrada no nível de articulação entre as representações (Vorstellungen, no alemão) manifestas na fala de seus pacientes, cujo sentido só poderia ser apreendido quando tomada uma representação em conjunto com outras representações. Basta realizar uma leitura atenta em “A

1. O grupo das neuroses atuais compreende a neurastenia, a neurose de angústia e a hipocondria; o grupo das psiconeuroses compreende, de um lado as neuroses de transferência histeria, neurose obsessiva e fobia - e, de outro, as neuroses narcísicas - esquizofrenia, paranóia (Freud, 1915). 


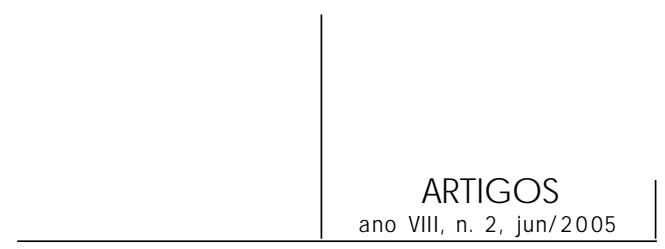

psicoterapia da histeria” para perceber que, na busca pela representação patogênica, os elementos ideativos que apareciam na incidência do método de pressão na testa não apresentavam qualquer significação se tomados isoladamente, mas apenas quando articulados a outros elementos que surgiam na incidência deste método (Freud, 1893). Nessa linha de pensamento, constatou-se que as representações estão ligadas entre si, formando um elo, donde se conclui que, no plano das Vorstellungen, o que se apresenta é um caráter de contigüidade, formador de uma cadeia.

O que emerge sob a pressão de minha mão nem sempre é uma lembrança "esquecida”; apenas nos casos mais raros é que as lembranças patogênicas reais acham-se tão freqüentemente à mão na superfície. É muito mais freqüente o surgimento de uma representação que é um elo intermediário na cadeia de associações entre a representação da qual partimos e a representação patogênica que procuramos. (Ibid., p. 286)

Se Freud estava interessado na história dos pacientes, é de se concluir portanto que, no que se refere aos apontados fatores históricos ligados à neurose, há uma dimensão de encadeamento do plano representativo. Contudo, no que se refere ao caráter determinante da representação patogênica - concebido nesse momento por ele como núcleo patógeno - constata-se um importante salto teórico que se encontra na própria origem da invenção da psicanálise. Freud concluiu, segundo constatações clínicas, que as representações patogênicas que buscava não correspondiam a lembranças de fatos reais do passado; constituíam fantasias de sedução - realizada por parte de um adulto apenas suposto - remetidas a épocas remotas da infância, que apareciam no sentido de rechaçar a sexualidade do próprio indivíduo (Freud, 1906). Com esta conclusão, inferiu que o sintoma psiconeurótico é o resultado do recalcamento de uma representação incompatível na consciência, ligada à sexualidade, que permanece no inconsciente e retorna, sob os processos de deslocamento e condensação, na formação dos sintomas. A partir desse ponto de vista, pôde-se lançar o conceito de recalque como "pedra angular” da psicanálise e o conceito de inconsciente como instância psíquica (Freud, 1900).

Esta operação leva-nos a pensar sobre as relações de historicidade ao nível da linguagem, as quais, sobre o pano de fundo da sexualidade, caracterizam uma concepção de história peculiar à psicanálise. Freud (1906) afirmou, em alguns momentos, que os fatores sexuais envolvidos nos sintomas psiconeuróticos estavam relacionados a questões do passado - em oposição às neuroses atuais. Mas a questão que incide justamente na oposição passado/presente pode, numa leitura mais aprofundada de seus trabalhos, ser rediscutida e repensada. Percebese que Freud, ao falar de questões da "infância” do paciente, referia-se a algo além 


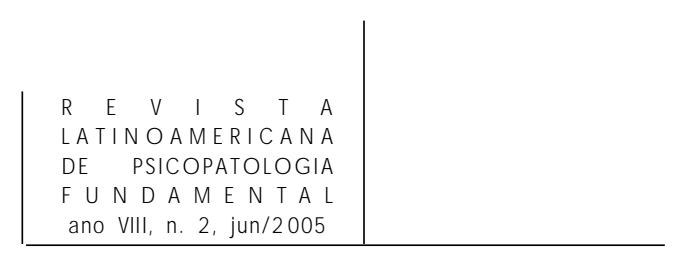

de uma simples concepção de passado. Sua posição é clara quando realiza uma pontuação fundamental quanto a natureza do termo "infantil", referindo-se às apontadas mudanças teóricas relativas à questão do trauma e da sexualidade. Ele afirma: “... os 'traumas sexuais infantis' foram substituídos, em certo sentido, pelo 'infantilismo da sexualidade’” (p. 261). A sexualidade tem um caráter infantil, no que se refere às questões do inconsciente. Acima de tudo, Freud (1905) não está se referindo a um "infantil" sob o ponto de vista simplesmente temporal, mas a uma sexualidade - humana - que não pode ser concebida de outra maneira na psicanálise senão como sexualidade infantil, à medida que a constituição do inconsciente ocorre sob uma via sexual infantil ligada ao princípio de prazer. O inconsciente tem, aqui, um caráter de atemporalidade, tal como ele aborda em "O inconsciente” (1915). Isso pontua que não se trata simplesmente de questões do passado, mas de questões remetidas a um nível mais complexo, da ordem de uma trama de representações (Vorstellungen), e de sua articulação como cadeia de associações. $^{2}$

É nesse nível que a concepção de linguagem no campo do inconsciente toma importância no ponto mesmo em que se faz notar de uma maneira indispensável a visão de Lacan sobre o significante.

Lacan traz à psicanálise o estruturalismo lingüístico dando ênfase ao inconsciente como uma estrutura de linguagem, em que o significante toma um estatuto privilegiado. Do inconsciente, o que se apreende é uma rede de significantes, conjugados pela potência de sentido que na sua articulação se estabelece. Um significante está sempre remetido a outros significantes, e apenas nessa combinação o sentido pode advir. Para Lacan (1956), “... todo verdadeiro significante é, enquanto tal, um significante que não significa nada” (p. 209). No texto "A instância da letra no inconsciente ou a razão desde Freud" (1957), ele indica contudo que “... é na cadeia do significante que o sentido insiste, mas que nenhum dos elementos da cadeia consiste na significação de que ele é capaz nesse mesmo momento" (p. 506).

Nessa acepção, podemos enfocar de maneira precisa a discussão acerca da questão da historicidade no campo psicanalítico, demonstrando que não se pode abordar a historicidade sem tocar no tema da linguagem e da sexualidade. A apreensão do sujeito pela linguagem é o que, nos termos de um "deslizamento" da cadeia significante, dá condições ao sujeito de se relacionar com sua própria história. O sujeito é um efeito de sua própria história, na medida em que a incidência do

2. O termo "cadeia de associações" foi utilizado por Freud em seu trabalho "A psicoterapia da histeria” (1893) assim como "símbolos de seqüências de representações” (p. 292), “cadeias patogênicas de idéias” (p. 300) e “cadeia de pensamentos” (p. 312). 
significante vem macular a existência humana aos domínios da linguagem, promovendo nela - existência humana - uma dimensão historial. Outrossim, o sujeito se relaciona com sua história por meio da linguagem, o que constitui a historicidade como um campo de articulação da linguagem. Contudo, a linguagem é anterior ao sujeito e, antes mesmo de apropriar-se dela em sua subjetividade, o sujeito é determinado por ela, a partir do campo do Outro, lugar do qual o sujeito se constitui como efeito da operação da linguagem (Lacan, 1956).

No decurso das constatações de Freud o significante está presente de maneira inequívoca. No aparecimento de um significante, Freud (1893) nada tinha a fazer; contudo, sua busca pelo encadeamento da rede de idéias demonstra que o que vinha a posteriori era o que dava possibilidades de significação aos elementos primeiros da cadeia, constituindo-se assim uma estrutura retroativa. Nessa espera, a escuta psicanalítica começava então a se constituir como ponto de ancoragem da historicização realizada pelo encadeamento dos significantes. Desde o início, a teoria freudiana carrega em si esses apontamentos, contudo fora da explicação apoiada no estruturalismo lingüístico. Isso fica claro principalmente nos momentos em que Freud se centra de maneira inelutável aos enlaces do sujeito com sua história e às conseqüências da representação no campo da subjetividade.

Enfoquemos ainda aquilo que se configura como sendo da ordem do sexual no campo do inconsciente, daquilo que definimos como sendo condição de possibilidade da constituição da historicidade na subjetividade humana. Entendese com Freud que um dos pilares de sua teoria está na concepção de que o aparelho psíquico tem como função manter o mais baixo possível o nível da tensão, função principal de promover a descarga da excitação e se livrar das quantidades de estimulação. No "Projeto para uma psicologia científica" (1895), Freud descreve o aparelho psíquico em termos de processos neuronais supostos. Esse texto toma uma importância indiscutível para o desenvolvimento da reflexão teórica atual.

Para Freud (ibid.), o aparelho neuronal é um aparelho de retardo do estímulo, em que, no terreno dos "neurônios impermeáveis" $(\psi)$, as quantidades de estimulação (Qn) produzem "trilhamentos”, "facilitações” (Bahnung, no alemão). A memória se daria no plano da diferença, no sentido de que as marcas produzidas em diferentes intensidades no sistema impermeável produziriam diversos níveis de facilitações. Assim, o afluxo da quantidade de estimulação teria caminhos bem definidos, trilhamentos que determinariam dessa forma todo o esquema da memória. Sob o processo das vias de condução no sistema neuronal impermeável $(\psi)$, a energia flui no sentido da descarga, liberada pela facilitação (Bahnung). É no plano do trilhamento que se dá efetivamente o que Freud denominou "processo primário", pois à medida que a Qn flui mediante as facilitações, torna-se viável a descarga pelo princípio de prazer. Contudo, a 


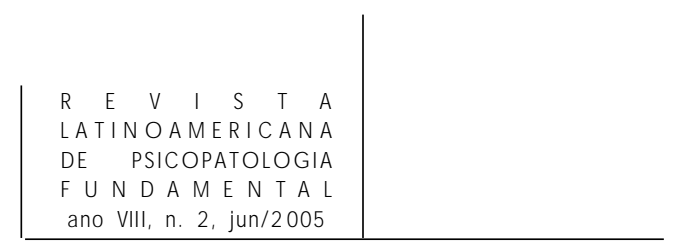

descarga não pode atingir o nível zero de excitação, supondo-se que a isso sobreviria uma verdadeira extinção do aparelho. A função atribuída ao funcionamento do princípio do prazer é, decisivamente, a regulação dessa quantidade, o que é desempenhado pelo sistema impermeável como uma retenção de um certo nível de $Q n$ (ibid.).

O sistema de memória é definido por Freud, assim, em termos de trilhamentos (Bahnung). Lacan (1959) chama atenção a este ponto, essencial para o entendimento da cadeia significante:

Bahnung evoca a constituição de uma via de continuidade, uma cadeia, e penso até que isso pode ser aproximado da cadeia significante, uma vez que Freud diz que a evolução do aparelho $\psi$ (sistema impermeável) substitui a quantidade simples pela quantidade mais a Bahnung (trilhamento), ou seja, sua articulação. (p. 53)

A viabilidade de rememoração pode apenas se dar pela articulação entre representações (Vorstellungen), sob o ponto de vista de um aparelho de memória o qual, tal como nos descreve Freud e reinterpreta Lacan, se circunscreve pela incidência do significante:

É entre percepção e consciência que aquilo que funciona no nível do princípio do prazer se insere. Ou seja, o quê? - os processos de pensamento na medida em que regulam, pelo princípio do prazer, o investimento das Vorstellungen e a estrutura na qual o inconsciente se organiza, a estrutura na qual a subjacência dos mecanismos inconscientes se flocula, o que constitui o grumo da representação, ou seja, algo que tem a mesma estrutura (...) do significante. Isso não é simplesmente Vorstellung, mas como o escreve Freud mais tarde em seu artigo sobre o inconsciente, Vorstellungsrepräsentanz, o que constitui a Vorstellung como um elemento associativo, combinatório. (Lacan, 1959, p. 80)

Partindo desta seqüência de afirmações, podemos indicar que a história pode apenas se constituir como passado para o sujeito à medida que um significante leva a outro no jogo das articulações de memória, sempre subsumidas à questão do prazer e da sexualidade. Concluindo com Lacan:

... é preciso sempre supor uma organização anterior, pelo menos parcial, de linguagem, para que a memória e a historicização possam funcionar. Os fenômenos de memória pelos quais Freud se interessa são fenômenos de linguagem. (...). O significante é, pois, dado primitivamente, mas ele não é nada enquanto o sujeito não o faz entrar em sua história (...). O desejo sexual é com efeito o que serve ao homem para se historicizar. (Lacan, 1956, p. 180; grifos meus)

Portanto, a história está decisivamente vinculada ao significante e à sexualidade. “A história não é o passado”, nos adverte Lacan (1954, p. 21). A 
experiência psicanalítica não tem a ver propriamente com algo da ordem do passado vivido. Trata-se de uma reconstituição das lacunas que se fazem sentir sob a marca do recalque, e seus rechaços fantasmáticos, sob fato de que, o que se apreende na historicização, é a cadeia significante.

\section{A dimensão da historicidade e a questão sobre a psicossomática}

Como apontamos, a menção de Freud sobre os fatores históricos da sexualidade está remetida fundamentalmente ao "infantilismo da sexualidade”. Os conteúdos mnemônicos que constituem o resultado da afetação da sexualidade no campo do sujeito revelam que supostos "fatos traumáticos” do passado não passam de uma construção fantasmática à própria sexualidade do sujeito "sexualidade infantil". Quando Freud fala, portanto, de fatores históricos da sexualidade, está se referindo, sob o ponto de vista de uma leitura apurada de sua obra, à articulação das Vorstellungsrepräsentanzen ou, nos termos de Lacan, à conexão entre dois ou mais significantes. A história se constitui na abertura à articulação significante, em seu deslizamento e, sob o ponto de vista da neurose, em sua dimensão causal. Freud demonstra a importante associação entre o sintoma e fatores de linguagem inferindo a eles um vínculo decisivo a questões sexuais históricas. É nesse ponto que opõe as psiconeuroses às ditas "neuroses atuais".

As neuroses "atuais", como Freud as concebia no início de suas teorizações, estão remetidas a fatores contemporâneos da sexualidade, ou seja, seus sintomas são resultado direto de uma excitação sexual que não foi psiquicamente descarregada ou não passou pela elaboração simbólica, não se articulou a uma série psíquica. São conseqüências diretas oriundas da excitação que produzem sintomas corporais concretos, como dispnéia, problemas cardíacos ou cefaléia. Eis o motivo pelo qual insistimos na ênfase de uma apreensão da historicidade na psiconeurose segundo um modelo de linguagem ligado ao princípio de prazer, ou seja, ao escoamento da libido: a neurose "atual" se localiza num ponto onde a libido não foi escoada.

O conceito de neurose atual foi, como afirmamos no início, amplamente utilizado no pensamento contemporâneo sobre as patologias psicossomáticas e, pensamos, deve ser cuidadosamente tratado e minuciosamente verificado na obra freudiana. Os pensadores que mais se utilizaram deste conceito são aqueles que compõem a Escola de Psicossomática de Paris, orientados pelo psicanalista P. Marty. Como foi apontado alhures, contudo (Quintella, 2003), a concepção psicossomática desses autores deve ser revista, já que, sob o modelo da neurose 


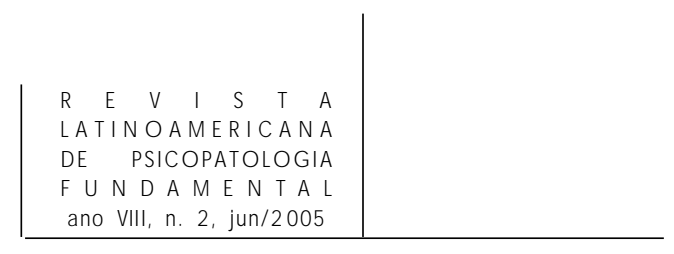

atual, sua teoria é questionável. Marty (1998) centra-se no ponto de vista econômico, isolando radicalmente o fenômeno psicossomático de qualquer implicação psiconeurótica devido a uma suposta precariedade do pré-consciente, um déficit constitucional de representações característico dos pacientes somatizantes. Por esse fator, o excesso da excitação, dentro de um paradigma dualista corpo-mente, não entraria nas redes psíquicas, não encontraria escoamento e não produziria patologias psiconeuróticas, mas sim fenômenos somáticos. Esses fenômenos somáticos, em contrapartida, não entram em série na tentativa de historicização sob tratamento psicanalítico; capturados pela objetividade do discurso médico (Clavreul, 1983), muitos dos pacientes em questão apresentam um discurso objetivante, segundo Marty (1993) um "pensamento operatório", e são localizados num plano distinto do quadro psiconeurótico, na medida em que o aparelho psíquico desses pacientes é tomado como diferente em sua constituição, ou seja, pobre de representações, sendo assim, limitado no seu aspecto associativo. Um paciente "psicossomático" não apresentaria, nesse âmbito, sintomas e características psiconeuróticas, devido à insuficiência de representações conferida à sua constituição psíquica; em contrapartida, segundo este modelo teórico, um psiconeurótico típico estaria "protegido" de doenças psicossomáticas, devido à sua ampla capacidade de elaboração das excitações e promoção de escoamento psíquico das mesmas (Ferraz, 1997).

Entretanto, a neurose atual, como vimos (Quintella, 2003), é parte integrante da psiconeurose, constitui-se como núcleo desta e está intimamente vinculada a ela. É assim que a encontramos na obra freudiana, conforme, por exemplo, uma afirmação sobre as "neuroses mistas", onde se encontram articulados sintomas psiconeuróticos com sintomas "atuais". Freud (1893) afirma:

A razão por que as neuroses mistas ocorrem com tanta freqüência é que seus fatores etiológicos se acham muitas vezes entremeados, às vezes apenas por acaso, outras vezes como resultado de relações causais entre os processos de que derivam os fatores etiológicos das neuroses. (p. 275)

Como demonstra Freud, as neuroses atuais estão entrecruzadas com as psiconeuroses em suas relações etiológicas. A questão da etiologia e da conexão entre psiconeuroses e neuroses atuais não foi muito aprofundada por ele. Contudo, podemos caracterizar este ponto como crucial para o entendimento de que, tal como se observa na abordagem freudiana da neurose atual, não é necessária a existência de déficit de representações para a ocorrência de descargas corporais lesivas ao organismo. Tampouco os pacientes psiconeuróticos se acham "protegidos" da neurose atual. Ao contrário, de acordo com Freud, grande número de pacientes psiconeuróticos apresentavam também neuroses "atuais", a ponto de ele localizar a última como núcleo e complexo eclosivo da psiconeurose. 


\section{ARTIGOS}

ano VIII, n. 2, jun $/ 2005$

O fator de oposição entre os dois grupos de neuroses, que se centra no fator histórico ou no fator atual, vai tomando, a partir disso, novas configurações no desenrolar da teoria de Freud. É importante aqui pontuar, avançando neste tema, que sua relativização a respeito dos fatores sexuais históricos na psiconeurose quando acentuamos que trata-se aí, não de fatos reais do passado, mas de uma rede de construções fantasmáticas, de uma articulação significante - pode atingir, em contrapartida, a concepção psicanalítica sobre a "atualidade" de um sintoma somático. Desejamos propor, sob esse apontamento e a partir do ponto de vista da ligação intrínseca entre neurose atual e psiconeurose, a relativização do termo atual, no sentido de se pensar uma descarga corporal vinculada não apenas a fatores presentes, atuais. É preciso questionar até que ponto a neurose atual não estaria também vinculada, de uma forma mais complexa, a questões históricas e à experiência do sujeito na sua relação com a linguagem. Não podemos pensar esse modelo de descarga corporal de maneira desmembrada de questões "psiconeuróticas" e, portanto, da questão da historicidade e da linguagem. Conforme aponta Rocha (2000), num trecho que consideramos de substancial importância:

Como quer que seja, vale a pena lembrar que, para Freud, não existem as "neuroses puras", mas, sim, as "neuroses mistas". Assim sendo, é quase impossível conceber uma neurose atual que se esgote no presente sem ligação alguma com o passado e que seja puramente atual. Nem também se poderia pensar uma psiconeurose que não tivesse repercussão no aqui e agora do tempo presente. (p. 57)

Seguindo essa linha de raciocínio, destacamos um apontamento de Freud que avaliamos imprescindível para esta discussão. Em "Um estudo autobiográfico" (1925), referindo-se aos primórdios de suas teorizações, ele afirma:

Desde aquela época não tive oportunidade de voltar à pesquisa das "neuroses atuais", nem essa parte do meu trabalho foi continuada por outro. Se hoje lanço um olhar retrospectivo aos meus primeiros achados, eles me surpreendem como sendo os primeiros delineamentos toscos daquilo que é provavelmente um assunto muito mais complicado. Mas no todo, ainda me parecem válidos. Teria ficado muito satisfeito se tivesse sido capaz, posteriormente, de proceder a um exame psicanalítico de mais alguns dos casos de neurastenia juvenil, mas infelizmente não surgiu a ocasião. A fim de evitar concepções errôneas, gostaria de esclarecer que estou longe de negar a existência de conflitos mentais e de complexos neuróticos na neurastenia. Tudo que estou afirmando é que os sintomas desses pacientes não são mentalmente determinados ou removíveis pela análise, mas devem ser considerados como conseqüências tóxicas diretas de processos químicos sexuais. (p. 32)

Freud faz questão de dizer que não nega a existência de "conflitos mentais" e "complexos neuróticos" na neurose atual. Por outro lado, diz que a neurose 


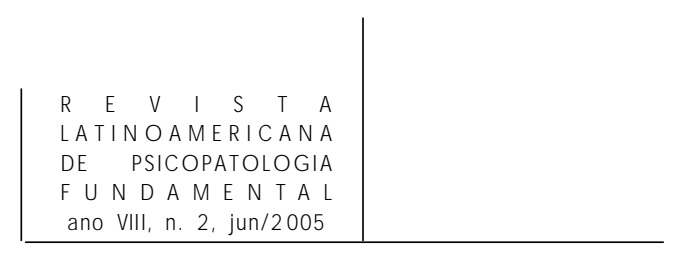

atual não é "mentalmente determinada". Pensemos se isto não deve ser examinado com cuidado. A neurose atual, como ele aborda, é o resultado de um processo que não passou pelo recalque nem pelas operações de condensação e deslocamento tal como ocorre na histeria, na neurose obsessiva e na fobia. Não há valor de metáfora no sintoma atual, nem de metonímia - não houve aí, portanto, deslizamento significante. Ora, se há na lógica da psiconeurose uma questão histórica, é porque esses referidos processos se fazem sentir claramente no sintoma psiconeurótico. Em outras palavras, poderíamos dizer que os sintomas psiconeuróticos imprimem ao sujeito uma historicidade, ali mesmo, em sua própria estrutura, o que não aparece nas "neuroses atuais". Isso não invalida a hipótese de que o sintoma "atual" esteja vinculado efetivamente a "conflitos mentais", ou "complexos neuróticos" existentes nas psiconeuroses, conforme não nega Freud. Freud pontua muitas vezes, como colocamos, uma importante articulação entre a psiconeurose e a neurose atual, de modo que, o que se apreende da ligação entre elas é a existência de uma verdadeira aglutinação (ibid.). A partir disso, convém refletir sobre a importância desta ligação, desta aglutinação, e pensar que algo de muito peculiar deve ocorrer na articulação da linguagem para que a excitação não prossiga na passagem das Vorstellungen, produzindo descargas corporais e sintomas somáticos que resultam desta excitação. Cabe então questionar, saindo de um ponto de vista eminentemente economicista, que peculiaridade é essa na articulação da linguagem, dimensionar a relação do sujeito com o Outro nessas manifestações, e indagar que pontos de sua história - história vivida pelo sujeito como elementos do "passado" - não entram nessa ordem de condensação e deslocamento, quando nos deparamos com a incidência de uma neurose "atual", e a partir desse pensamento, de um fenômeno psicossomático.

Essa questão nos remete ao ponto de vista da dimensão da linguagem no campo da Vorstellungsrepräsentanz, ou seja, do significante e de sua articulação. Lacan (1964) localiza o fenômeno psicossomático na indução significante, inferindo a ele uma ligação crucial com a linguagem.

A psicossomática é algo que não é um significante, mas que, mesmo assim, só é concebível na medida em que a indução significante, no nível do sujeito, se passou de maneira que não põe em jogo a afânise do sujeito. (p. 215)

Isso diz respeito efetivamente, do ponto de vista de Freud e das colocações aqui realizadas, ao escoamento das excitações ao nível da articulação significante e do princípio de prazer, ou seja, da sexualidade. Para Lacan, está implicado no fenômeno psicossomático um conjunto de significantes que permanecem "solidificados", e que não remetem a outros significantes, impedindo o efeito afanísico do sujeito e não havendo, neste ponto, deslizamento da cadeia significante. A descarga corporal sobrevém do significante "solidificado" que, 


\section{ARTGOS}

ano VIII, n. 2, jun/2005

articulando com Freud, impede o escoamento psíquico das excitações e produz lesões ao nível do órgão.

É importante este remanejamento teórico do modelo de “descarga” corporal circunscrito na obra freudiana à neurose atual, a partir do momento em que se dá ênfase ao papel da linguagem na psicossomática e à importância da relação do sujeito ao Outro, redimensionando-se a psicossomática a uma concepção de linguagem capaz de apontá-la como um fenômeno ligado decisivamente ao significante.

Para efeito de compreensão acerca da implicação do significante nesses fenômenos, encontramos uma passagem de Pontalis (1981), que talvez possa ilustrar essa questão. Abordando o tema da reação no contexto do sujeito, ele coloca:

Encontramos na história infantil desses pacientes - uma história pobre de lembranças e revivescências -, principalmente, palavras proferidas, na maioria das vezes, pela mãe. Esses ditos têm valor de atos. Como veredictos sem apelação, sentenças recebidas como negações de justiça, eles não são passíveis de nenhuma recomposição que os relativize e que, ao mesmo tempo, relativize a imagem e o poder daquele ou daquela que os enuncia. Absolutos, só podem suscitar, em contrapartida, uma reação. Por isso, não raro vemos sobrevir na análise desses pacientes um "agir" externo ou somático. (p. 62)

Lacan (1964) aponta então: "Essa solidez, esse apanhar a cadeia significante primitiva em massa, é o que proíbe a abertura dialética que se manifesta no fenômeno da crença” (p. 225). Ou seja, o sujeito não responde no nível da construção fantasmática ao desejo do Outro. Este não se apresenta como enigma, mas se impõe ao sujeito, impedindo-o de dialetizar. Lacan defende que o significante se solidifica na cadeia, impedindo o deslizamento e a articulação com outros significantes (o que seria resultado da dialética do sujeito frente ao enigma do desejo).

Sob esta perspectiva, o campo histórico não estaria tão fora de questão, à medida que se focaliza, no terreno da indução significante, a eclosão de uma lesão psicossomática. Tal ocorrência não está ligada necessariamente a uma determinada estrutura, já que se concebe este fenômeno da "holofrase"3 de maneira pontual e não constitucional ou estrutural, da mesma maneira que se verifica, segundo relatos de psicanalistas (cf. Dejours, 1998), que fenômenos psicossomáticos aparecem também em quadros psiconeuróticos.

3. O termo "holofrase" diz respeito, na teoria lacaniana, à solidificação do par significante S1 S2, entre os quais não há intervalo e, portanto, não há passagem. A "holofrase” designa uma palavra ou uma frase que "diz tudo", uma palavra absoluta, irredutível. Nesse sentido, podemos entender que, a respeito de uma palavra absoluta que se impõe pelo Outro, o sujeito nada tem a produzir ou nada tem a dizer. 


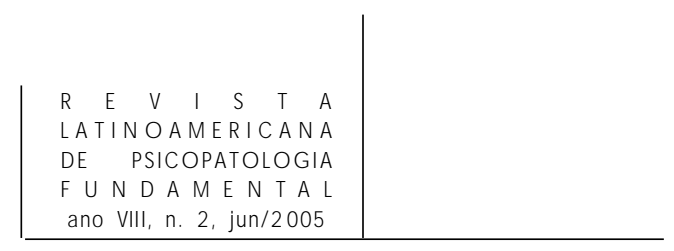

A psicossomática se choca, permanentemente, com a questão da historicidade. Avaliamos que, partindo da linha de pensamento das questões colocadas, possamos pensar perspectivas consistentes sobre a natureza do fenômeno psicossomático, coerentes com o discurso psicanalítico. Percebe-se a problemática apresentada a Freud pelas neuroses “atuais” referente aos solavancos da sexualidade no conflito humano, dirigidas a manifestações de nível somático. Se a neurose atual e o fenômeno psicossomático estão nos limites do "sentido", do "simbólico", da articulação significante, cabe questionar, em contrapartida, se esses "solavancos" psicossomáticos seriam possíveis se o ser humano não fosse um ser de linguagem, um ser atravessado pelo significante.

Longe de esgotar estas questões, tivemos aqui como objetivo, mediante uma localização renovada do modelo da neurose atual na teoria psicanalítica - dando ênfase à questão da historicidade em oposição à atualidade - abrir caminho para o campo dos efeitos do significante na constituição da subjetividade humana, sob perspectiva de pesquisa relativa ao domínio da linguagem nos estudos concernentes ao campo psicossomático. Cabe nessa direção indagar sobre as relações do significante com a ordem do corpo e, no aprofundamento dessas questões, apontar como crucial a discussão a respeito do pensamento dualista que muitas vezes permeia as abordagens em psicossomática vigentes na atualidade.

Consideramos ainda, diante de tais conclusões, que a teoria martyniana apresenta problemas cruciais, devendo ser revista no campo das concepções psicossomáticas. Nesse ínterim, avaliamos importante o aprofundamento teórico acerca deste tema, levando-se em consideração os apontamentos realizados para o estabelecimento de concepções que abarquem o "fenômeno psicossomático" como elemento decisivamente problemático para a psicanálise, na medida em que concerne não apenas ao domínio do saber psicanalítico, mas comparece também no terreno da medicina e dos estudos sobre o funcionamento orgânico. A psicanálise se vê, contudo, convocada a oferecer elementos teóricos que direcionem essa problemática a possíveis soluções. Para tanto, faz-se necessária uma discussão aprofundada desses temas com a finalidade de construir caminhos que nos levem a algumas possíveis conclusões e que ofereçam consistencialidade ao contexto da teoria psicanalítica.

\section{Referências}

Clavreul, J. A ordem médica - poder e impotência do discurso médico. São Paulo: Brasiliense, 1983.

Dejours, C. Biologia, psicanálise e somatização. In: FerRAz, F. C. \& Volich, R. M. (orgs.). 


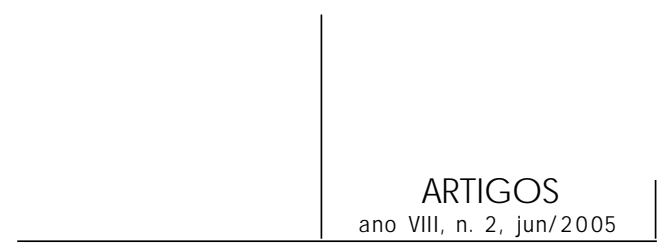

Psicossoma II - Psicossomática psicanalítica. São Paulo: Casa do Psicólogo, 1998.

Ferraz, F. C. Das neuroses atuais à psicossomática. In: Ferraz, F. C. e Volich, R. M. (orgs.). Psicossoma - Psicossomática psicanalítica. São Paulo: Casa do Psicólogo, 1997. Freud, S. (1893). A psicoterapia da histeria. In: Edição Standard Brasileira das Obras Psicológicas Completas. Rio de Janeiro: Imago, 1996. v. II, p. 271-316.

(1895). Projeto para uma psicologia científica. In: Edição Standard Brasileira das Obras Psicológicas Completas. Rio de Janeiro: Imago, 1996. v. I, p. 347-454

(1898). A sexualidade na etiologia das neuroses. In: Edição Standard Brasileira das Obras Psicológicas Completas. Rio de Janeiro: Imago, 1996. v. III, p. 251-270. (1900). A interpretação dos sonhos. In: Edição Standard Brasileira das Obras Psicológicas Completas. Rio de Janeiro: Imago, 1996. v. IV e V.

(1905). Três ensaios sobre teoria da sexualidade. In: Edição Standard Brasileira das Obras Psicológicas Completas. Rio de Janeiro: Imago, 1996. v. VII, p. 119-229.

(1906). Minhas teses sobre o papel da sexualidade na etiologia das neuroses. In: Edição Standard Brasileira das Obras Psicológicas Completas. Rio de Janeiro: Imago, 1996. v. VII, p. 255-65.

(1915). O inconsciente. In: Edição Standard Brasileira das Obras Psicológicas Completas. Rio de Janeiro: Imago, 1996. v. XIV, p. 171-222.

(1925). Um estudo autobiográfico. In: Edição Standard Brasileira das Obras Psicológicas Completas. Rio de Janeiro: Imago, 1996. v. XX, p. 11-78.

LACAN, J. (1954). O seminário. Livro 1. Os escritos técnicos de Freud. Rio de Janeiro: Jorge Zahar, 1986.

(1956). O seminário. Livro 3. As psicoses. Rio de Janeiro: Jorge Zahar, 1988.

(1957). A instância da letra no inconsciente ou a razão desde Freud. In: Escritos. Rio de Janeiro: Jorge Zahar, p. 497-533, 1998.

1997.

(1959). O seminário. Livro 7. A ética da psicanálise. Rio de Janeiro: Jorge Zahar,

(1964). O seminário. Livro 11. Os quatro conceitos fundamentais da psicanálise. Rio de Janeiro: Jorge Zahar, 1998.

Marty, Pierre. A psicossomática do adulto. Porto Alegre: Artes Médicas, 1993.

Mentalização e psicossomática. São Paulo: Casa do Psicólogo, 1998.

Pontalis, J. (1981). Não, duas vezes não. In: Perder de vista. Rio de Janeiro: Jorge Zahar, 1988. p. 54-73.

Quintella, R. R. A neurose atual e a psicossomática no campo psicanalítico. Pulsional Revista de Psicanálise, São Paulo, ano XVI, n. 169, p. 33-9, maio/2003.

Rocha, Z. Os destinos da angústia na psicanálise freudiana. São Paulo: Escuta, 2000. 


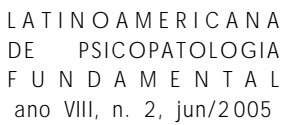

\section{Resumos}

Procuramos abordar aquí la cuestión de la concepción de historicidad en psicoanálisis, en contrapunto al concepto de neurosis actual, lo cual sirve de base para la teorización contemporánea en psicosomática. Realizamos una revisión crítica de la neurosis actual, bajo el prisma de una aglutinación neurosis actual - psiconeurosis, concibiendo historicidad y sexualidad articuladas al nivel del lenguaje. Finalmente, sugerimos que la neurosis actual debe ser abordada a partir de ese nivel, visto su ligación con la psiconeurosis, lo que puede fornecernos nuevas bases para que pensemos el fenómeno psicosomático.

Palabras claves: Neurosis actual, psiconeurosis, historicidad, sexualidad, lenguaje

Nous avons essayé d'aborder ici la question de la conception d'historicité en psychanalyse, en contrepoint du concept de névrose actuelle, qui sert de base à la théorisation contemporaine en psychosomatique. Nous avons mené une révision critique de la névrose actuelle, sous le prisme d'une agglutination névrose actuellepsychonévrose, en concevant l'historicité et la sexualité articulées au niveau du langage. Finalement, nous avons suggéré que la névrose actuelle devrait être abordée à ce niveau compte tenu de son rapport avec la psychonévrose, ce qui peut nous fournir de nouvelles bases pour penser le phénomène psychosomatique.

Mots clés: Névrose actuelle, psychonévrose, historicité, sexualité, langage

We searched here for broaching the matter of the conception about historicity in psychoanalysis, in contrast to the concept of 'actual' neurosis, which serves as basis to the contemporary theorization in psychosomatic. We carried out a critical review of actual neurosis, under the point of view of an agglutination actual neurosis psychoneurosis, conceiving historicity and sexuality articulated to the language level. Finally, we suggest that actual neurosis has to be broached by this level, verified its conexion with psychoneurosis, which can provide us with new basis to think of the psychosomatic phenomenon.

Key words: Actual neurosis, psychoneurosis, historicity, sexuality, language

Versão inicial recebida em outubro de 2004

Aprovado para publicação em janeiro de 2005 